\title{
Pemanfaatan Media Pembelajaran Dengan Menggunakan Multimedia Power Point Untuk Konsep Sistem Saraf Di SMP Negeri 11 Kabupaten Sorong
}

\author{
Novita Wulandari ${ }^{1}$, Ninik Septyani ${ }^{2}$, Jusrianto $\mathrm{AS}^{3}$ \\ Universitas Pendidikan Muhammadiyah Sorong ${ }^{1,3}$ Universitas Negeri Makassar $^{2}$ \\ novitawulandariumar@gmail.com,nisep1096@gmai.com, jusrianto33@gmail.com
}

\begin{abstract}
Abstrak: Berbagai permasalahan yang dihadapi siswa di sekolah ini, terlebih di kelas II dengan permasalahan antara lain prestasi belajar yang rendah, yang mengakibatkan kurang adanya motivasi untuk bersemangat belajar, dan siswa tidak memiliki sebuah motivasi untuk saling bersaing dalam memperoleh nilai. Hal ini terjadi karena system proses pembelajaran di SMPN $11 \mathrm{Kab}$. Sorong hanya menggunakan proses ceramah, guru menerangkan secara konvensional tanpa menggunakan media yang menunjang seperti teknologi atau alat disaat proses pembelajaran berlangsung. Untuk meningkatkan proses pembelajaran siswa perlu sentuhan teknologi, khususnya multimedia salah satu media yang paling cepat dan gampang untuk guru pelajari dan sajikan ke siswa yaitu power point. Penelitian ini dilakukan dengan menggunakan media pembelajaran berupa program presentasi power point pada kelas II SMPN $11 \mathrm{Kab}$. Sorong. Penelitian ini ada tiga siklus, setiap siklusnya terdiri dari empat tahapan, yaitu: (1) perancangan: membuat scenario pembelajaran menggunakan power point, (2) Tindakan: melaksanakan scenario pebelajaran seperti yang telah direnanakan, (3) Observasi: melakukan pengamatan terhadap pelaksanaan tindakan menggunakan lembar observasi dan alat evaluasi, dan 4) Refleksi: melakukan analisis data hasil observasi dan evaluasi, hasil refleksi digunakan untuk perbaikan pembelajaran pada siklus selanjutnya Dari hasil penelitian maka dapat disimpulkan bahwa penerapan bembelajaran dengan menggunakan media komputer bentuk power point dapat meningkatkan motivasi dan hasil belajar siswa kelas II SMPN 11 Kab. Sorong tahun pelajaran 2019/2020.
\end{abstract}

Kata Kunci : Multimedia, Power Point, Motivasi, Hasil Belajar

Abstract: Various considerations that discuss students in this school, departing in class II with debates including the low learning achievement, which discuss kuranf which increases motivation to learn, and students do not have the motivation to compete with each other in obtaining grades. This happens because the learning process system in SMPN 11 Kab. Sorong only uses the lecture process, the teacher explains conventionally without using supporting media such as technology or tools while the learning process is taking place. To improve the learning process students need to add technology, especially multimedia, one of the fastest and easiest media for teachers to understand and present to students is the power point.

This research was conducted using instructional media in the form of power point presentation programs in class II SMP $11 \mathrm{Kab}$. Sorong This study has three cycles, each cycle consisting of four stages, namely: (1) design: create learning scenarios using power points, (2) Actions: implement learning scenarios as planned, (3) Observation: make observations on the implementation of actions using observation sheets and evaluation tools, and 4) Reflection: analyzing data on observations and evaluations, reflection results are used to improve learning in the next cycle. From the results of the research above, it can be concluded that the application of learning using computer media in the form of power point can increase 
motivation and learning outcomes of Grade II students of SMPN 11 Kab. Sorong 2019/2020 school year.

Keywords: Multimedia, Power Point, Motivation, Learning Outcomes

\section{Pendahuluan}

Proses pembelajaran, terdapat beberapa komponen, dua diantaranya adalah guru dan siswa. Agar proses pembelajaran berhasil, guru harus aktif diantaranya dalam hal mendorong siswa untuk aktif belajar dan memberikan pengalaman belajar yang memadai kepada siswa.

Menurut Winkel (1987), pembelajaran berlangsung di dalam kelas, dapat ditemukan beberapa komponen yang bersama-sama mewujudkan proses tersebut. Komponen-komponen tersebut antara lain prosedur didaktif, media pembelajaran, pengelompokan siswa dan materi pelajaran. Peranan dalam membimbing pada dasarnya ikut dalam prosedur didaktif.

Observasi awal yang telah dilakukan diketahui bahwa SMPN 11 Kab. Sorong ini merupakan Negeri. Dengan beberapa perbedaan dalam hal mata pelajaran tambahan dan alokasi waktunya. Lokasi SMPN ini terletak disekitar pemukiman masyarakat dan sekolah ini lumayan ramai di kunjungi karena berada di wilayah strategis. Siswa SMPN ini umumnya berasal dari pondok $70 \%$ asli anak papua, dan $30 \%$ pendatang di papua namun sudah bertempat tinggal lama.

Mata pelajaran Biologi di sekolah ini diajarkan dengan satu metode yaitu ceramah dengan guru menjelaskan dan siswa cenderung hanya mendengar tanpa ada variasi seperti pemanfaatan media dan sebagainya. Alasan dari kegiatan belajar mengajar yang monoton ini adalah kurangnya peralatan laboratorium dan fasilitas yang lainnya menyebabkan kegiatan seperti praktikum sangat sukar diterapkan.

Siswa yang terdapat di SMP ini pada umumnya mempunyai prestasi belajar rendah, meskipun ada beberapa yang berprestasi sangat menonjol, hal ini mengakibatkan kurang adanya semangat belajar (motivasi) untuk saling bersaing dalam memperoleh nilai.

Berdasarkan informasi dari guru Biologi, nilai rata-rata ulangan harian pada sistem pencernaan adalah 6,3 dengan ketuntasan $56 \%$. Kondisi ini menggambarkan bahwa pemahaman siswa dalam proses pembelajaran masih rendah sehingga menyebabkan hasil belajar siswa cenderung rendah. Begitu pula dari wawancara dengan siswa diperoleh hasil bahwa siswa mengalami kesulitan mempelajari sistem saraf karena banyaknya konsep yang sulit dipahami oleh siswa serta sulit dihafal, dan siswa memerlukan media pembelajaran yang dapat membantu meningkatkan motivasi dan hasil belajar siswa.

Permasalahan di SMPN tampaknya disebabkan oleh kurangnya guru memberikan variasi dalam pembelajaran sehingga pembelajaran hanya satu arah dan siswa tidak dilibatkan secara aktif. Sarana pembelajaran yang kurang memadai serta materi sistem saraf yang sulit, ketiga faktor tersebut mempengaruhi rendahnya kompetensi siswa.

Permasalahan di atas memerlukan upaya penyelesaian agar siswa menjadi termotivasi untuk mempelajari sistem saraf sehingga meningkatnya kompetensi tercapai. Alternatif untuk memecahkan masalah tersebut di atas adalah dengan menggunakan media yang dapat menarik minat siswa untuk belajar biologi. Media tersebut yaitu komputer dan diharapkan siswa menjadi termotivasi sehingga hasil belajar biologi dapat meningkat yang berdampak pada meningkatnya kompetensi siswa. Ada beberapa alasan mengapa media pembelajaran dengan komputer dikembangkan antara lain sebagai variasi dalam pembelajaran, modern dan menarik, dapat menayangkan proses-proses yang sulit, belum banyak digunakan di sekolah-sekolah. 


\section{Metode Penelitian}

Penelitian tindakan kelas ini dilakukan di SMPN 11 Kab. Sorong, pada kelas II dengan jumlah siswa 38 anak. Jumlah anak laki-laki 25 dan jumlah anak perempuan 13. Kelas ini dipilih sebagai subjek penelitian karena berdasarkan hasil observasi awal yang dilakukan dengan wawancara dan angket diketahui bahwa pada kelas ini merupakan kelas yang paling bermasalah dalam proses belajar dengan indikator motivasi siswa yang kurang serta hasil yang rendah. Untuk meningkatkan motivasi siswa, guru meningkatkan variasi dalam proses pembelajaran dengan menggunakan media power point pada komputer.

Dalam Prosedur penelitian ini dibagi menjadi dua tahapan yaitu tahap persiapan dan tahap pelaksanaan penelitian. Pada tahap pelaksanaan dibagai menjadi beberapa siklus, masing-masing siklus terdiri atas empat tahapan, yaitu perencanaan, pelaksanaan/tindakan, observasi dan refleksi. Metode analisis data pada penelitian ini adalah metode deskriptif yang dihitung dengan cara: Rata-rata kelas

\section{Hasil dan Pembahasan}

Berdasarkan observasi terhadap pelaksanaan pembelajaran siklus I-III diperoleh hasil sebagai berikut.

1. Hasil Belajar

Setelah dilakukan analisis data hasil tes, perolehan nilai hasil belajar siswa pada tes siklus I-III dapat dilihat pada Tabel 1 di bawah ini.

Tabel 1. Perolehan nilai hasil belajar siswa dengan media power point pada system saraf

\begin{tabular}{|l|l|l|l|l|l|}
\hline \multirow{2}{*}{ No. } & \multicolumn{2}{|c|}{ Aspek } & \multicolumn{3}{c|}{ Hasil belajar } \\
\cline { 3 - 6 } & & $\begin{array}{c}\text { Observasi } \\
\text { awal }\end{array}$ & Siklus I & Siklus II & Siklus III \\
\hline 1. & Rata-rata & 52,81 & 60.62 & 67,96 & 75,95 \\
2. & Nilai tertinggi & 80 & 90 & 95 & 95 \\
3. & Nilai terendah & 35 & 35 & 45 & 60 \\
4. & Jumlah tuntas individu & 5 & 9 & 15 & 28 \\
5. & Persentase ketuntasan & $15,6 \%$ & $28,1 \%$ & 46,8 & $87,5 \%$ \\
\hline
\end{tabular}

Berdasarkan Tabel 1 di atas dapat dijelaskan bahwa pada siklus I nilai rata-rata siswa lebih besar dari nilai rata-rata sebelum tindakan. Demikian pula pada siklus II nilai rata-rata siswa lebih besar dari siklus I dan lebih besar dari nilai rata-rata siklus II pada siklus III. Pada siklus I dan II ketuntasan belajar siswa secara klasikal belum tercapai. Ketuntasan belajar siswa secara klasikal sudah tercapai pada siklus III. Ketuntasan belajar klasikal yang ditetapkan dalam indikator kinerja adalah minimal 85\% dari seluruh siswa memperoleh nilai > 6,5 .

2. Hasil Angket Motivasi Siswa

Hasil angket motivasi siswa selama pembelajaran dengan menggunakan power point disajikan pada Tabel 2 berikut ini. 
Tabel 2. Hasil angket motivasi siswa

\begin{tabular}{|c|c|c|c|}
\hline & $\begin{array}{c}\text { Tidak } \\
\text { Termotivasi }\end{array}$ & Biasa saja & Termotivasi \\
\hline Siklus I & $21,87 \%$ & $8,82 \%$ & $71,87 \%$ \\
Siklus II & $15,6 \%$ & $3,1 \%$ & $81,2 \%$ \\
Siklus III & $12,5 \%$ & $0 \%$ & $87,5 \%$ \\
\hline
\end{tabular}

Berdasarkan dari hasil data di atas, motivasi siswa selama proses pembelajaran pada tiap siklusnya semakin baik, sehingga dapat dikatakan bahwa siswa sudah mulai terbiasa dengan model pembelajaran yang diterapkan. Hal tersebut dapat dilihat dengan adanya peningkatan persentase sikap positif terhadap penggunaan media komputer dalam pembelajaran sistem saraf.

3. Hasil Observasi Aktivitas Siswa

Hasil pengamatan aktivitas siswa dalam proses belajar mengajar di kelas dengan menggunakan media komputer, dapat dilihat pada Tabel 3.

Tabel 3. Hasil pengamatan aktivitas siswa dengan penggunaan power point pada konsep sistem saraf.

\begin{tabular}{|l|l|c|c|c|}
\hline \multirow{2}{*}{ No. } & \multirow{2}{*}{ Aspek } & \multicolumn{3}{|l|}{ Persentase nilai rata-rata } \\
\cline { 3 - 5 } & & Siklus I & Siklus II & Siklus III \\
\hline 1. & Kemampuan mengoperasikan komputer & $100 \%$ & $100 \%$ & $100 \%$ \\
\hline 2. & Kemampuan memanfaatkan media & $50 \%$ & $87,5 \%$ & $93,75 \%$ \\
\hline 3. & Memperhatikan guru & $46,87 \%$ & $62,5 \%$ & $87,5 \%$ \\
\hline 4. & Kemampuan menjawab pertanyan & $46,87 \%$ & $87,5 \%$ & $93,75 \%$ \\
\hline 5. & Mengerjakan tugas & $78,12 \%$ & $86,87 \%$ & $100 \%$ \\
\hline
\end{tabular}

Hasil pengamatan yang telah dilakukan selama proses pembelajaran berlangsung diperoleh hasil bahwa pada pelaksanaan siklus I aktivitas siswa sudah cukup baik. Pada siklus pembelajaran selanjutnya mengalami peningkatan yang baik, hal ini dapat disebabkan siswa sudah mulai terbiasa dan ada ketertarikan dengan pembelajaran menggunakan media power point.

4. Hasil Observasi kinerja guru

Dalam melaksanakan pembelajaran pada setiap siklus, guru telah melaksanakan pembelajaran sesuai dengan Rencana Pembelajaran yang telah dipersiapkan. Berdasarkan pengamatan observer di kelas, diperoleh data yang disajikan pada Tabel 4 berikut ini. 
Tabel 4. Hasil Pengamatan Kinerja.

\begin{tabular}{|c|c|c|c|c|c|c|c|c|c|}
\hline \multirow{3}{*}{ No } & \multirow{3}{*}{ Aspek yang diamati } & \multicolumn{8}{|c|}{ Skala penilaian } \\
\hline & & \multicolumn{3}{|c|}{ Siklus I } & \multicolumn{3}{|c|}{ Siklus II } & \multicolumn{2}{|c|}{ Siklus III } \\
\hline & & & $\begin{array}{l}B \mid C \\
C\end{array}$ & $\overline{\mathrm{D}}$ & \begin{tabular}{l|l}
$\mathrm{A}$ & $\mathrm{H}$ \\
$\mathrm{H}$
\end{tabular} & & & & \begin{tabular}{l|l}
$\mathrm{C}$ & $\mathrm{D}$ \\
\end{tabular} \\
\hline 1 & Membuka Pelajaran & & $\sqrt{1}$ & & $T \sqrt{ }$ & & ti & & \\
\hline 2 & Menjelaskan tujuan & & V & & V & & i & & \\
\hline 3 & Memberikan motivasi & & $\sqrt{ }$ & & t & & h & & \\
\hline 4 & Memberikan pertanyaan & & V & & & b & & $\sqrt{ }$ & \\
\hline 5 & Menjawab pertanyaan siswa & & H & & T & & h & & \\
\hline 6 & Mengamati siswa mengerjakan tugas & $\sqrt{ }$ & & & $\sqrt{ }$ & & i & & \\
\hline 7 & Memberikan arahan pada siswa & $\sqrt{ }$ & & & $\sqrt{ }$ & & s & & \\
\hline 8 & Mengajak siswa membuat simpulan & t & & & T & & i & & \\
\hline
\end{tabular}

Keterangan:
A: Skor 4 : Sangat baik
C: Skor 2 : Cukup
B: Skor 3 : Baik
D: Skor 1 : Kurang

Berdasarkan hasil observasi kinerja guru pada Tabel 4, diperoleh bahwa kinerja guru pada pelaksanaan pembelajaran disetiap siklus sudah cukup baik. Dari siklus I sampai siklus II rata-rata mengalami peningkatan kinerja guru.

\section{Kesimpulan dan Saran}

Simpulan dari hasil penelitian ini adalah sbb. 1. Terjadi peningkatan prosentase jumlah siswa yang termotivasi dari hasil observasi sebesar $71,87 \%$ pada siklus I, $81,2 \%$ pada siklus II dan $87,5 \%$ pada siklus III. Meningkatnya motivasi siswa berpengaruh pada keaktifan siswa untuk mengikuti proses belajar mengajar. Juga berpengaruh pada pemahaman siswa pada materi sistem saraf. 2. Hasil belajar siswa meningkat dari observasi awal dengan jumlah tuntas belajar klasikal sebesar $28,1 \%$ pada siklus I, 46,8\% pada siklus II dan 87,5\% pada siklus III. Dari seluruh kesimpulan di atas menunjukkan bahwa penerapan pembelajaran pada konsep sistem saraf dengan menggunakan media pembelajaran komputer bentuk power point dapat meningkatkan motivasi dan hasil belajar siswa.

Dalam penelitian ini ada beberapa hal yang perlu mendapat perhatian yang merupakan saran penulis kepada para pembaca umumnya, guru, serta pihakpihak yang berkepantingan, yaitu : Media Pembelajaran Komputer bentuk power point dapat diterapkan pada kelas yang mempunyai karakteristik seperti kelas yang dijadikan subjek penelitian ini, dan Hendaknya pembelajaran dengan media komputer bentuk power point ini dicoba untuk diterapkan pada mata pelajaran yang lain.

\section{Daftar Pustaka}

Anonim. 1993. Kamus Besar Bahasa Indonesia. Jakarta : Balai Pustaka.

Arikunto, S. 2001. Dasar-dasar Evaluasi Pendidikan. Jakarta : Bumi Aksara.

Dahar, R.W. 1991. Teori-teori Belajar. Jakarta: Erlangga.

Darsono, M; A., Sugandhi; Martensi, Dj.; R. K. Sutadi \& Nugroho. 2000. Belajar 
dan Pembelajaran. Semarang: IKIP Semarang Press.

Daryanto. M. 1999. Evaluasi Pendidikan. Jakarta : PT. Rineka Cipta.

Departemen Pendidikan Nasional. 2001. Kurikulum Berbasis Kompetensi Mata

Pelajaran Biologi Untuk Sekolah Menengah Timgkat Perfama. Jakarta :

Departemen Pendidikan Nasional.

Dimyati. 1999. Belajar dan Pembelajaran. Jakarta : PT Rineka Cipta

Ekosiswoyo, R; Rifa'I, A dan Sutomo. 1996. Manajemen Kelas. Semarang : IKIP Semarang Press.

Jati, W. 2003. Model-Model Pembelajaran. Semarang. Departemen Pendidikan Nasional Jawa Tengah.

Mudzakir, A dan Sutrisno, J. 1997. Psikologi Pendidikan. Bandung : Pustaka Setia.

Muslich, M. 1994. Dasar-dasar Pemahaman Kurikulum 1994. Malang: YA3.

Natawijaya, R. 1985. Psikologi Pendidikan. Jakarta: Depdikbud.

Nasution, S. 2000. Berbagai Pendekatan Dalam proses Belajar dan Mengajar. Jakarta. Bumi Aksara.

Permana, B. 2004. Power Point 2003. Jakarta. PT. Elek Media Komputindo.

Purwanto, N. 1992. Psikologi Pendidikan. Bandung: CV. Remaja Karya.

Rohani, A. 1997. Media Instruksional Edukatif. Jakarta: Rineka Cipta.

Santoso, K. 2002. Pemilihan dan Pengembangan Media Pembelajaran.

Semarang: Proyek Peningkatan Tenaga Kependidikan dan Non

Kependidikan Menengah Dinas Pendiidkan Provinsi Jawa Tengah Kerja Sama Dengan UPT SBM Universitas Negeri Semarang.

Sadiman, A.S; R. Rahardjo; Haryono, dan A. Rahardjito. 1986. Media Pendidikan Jakarta: Rajawali Press.

Setiadi, R dan A. Akhril. 1999. Dasar-dasar Pemrograman Software Pembelajaran. Bandung: Jurusan Pendidikan Kimia FMIPA UPI bekerjasama dengan JICA.

Sudirman, N.Z. A. Rusyan dan T.Fathoni. 1992. Ilmu Pendidikan. Bandung: Remaja Rosdakarya.

Sudjana, N. 1989. Dasar-dasar Proses Belajar Mengajar. Bandung: CV. Sinar Baru.

Suharto. 1997. Pendekatan dan Teknik Dalam Proses Belajar Mengajar. Bandung Tarsito.

Thoha, M. 2001. Teknik Evaluasi Pemdidikan. Jakarta: PT. Raja Grafindo Persada.

Tim Pelatih Proyek PGSM Provinsi Jawa Tengah. 1999. Penelitian Tindakan Kelas. Semarang: Depdikbud Provinsi Jawa Tengah.

Tim Penelitian dan Pengembangan Wahana Komputer Semarang. 1997. Microsoft Office 97. Kerjasama Penerbit Andi Yogyakarta dengan Wahana Komputer Semarang. Winkel, W.S. 1989. Psikologi Pengajaran. Jakarta: PT. Gramedia 